\title{
Uma concepção normativa de coerência para uma teoria discursiva da argumentação jurídica*
}

\author{
Klaus Günther
}

Resumo: $\mathrm{O}$ autor introduz uma concepção normativa de coerência derivada da interpretação pragmática da aplicação de normas a casos concretos. Uma distinção é feita entre a justificação de uma norma e sua aplicação. No caso de normas morais, justificação e aplicação podem ser analisadas como dois procedimentos discursivos distintos que dão origem a aspectos distintos do princípio da imparcialidade. Justificação imparcial requer um procedimento por meio do qual todos os interesses envolvidos sejam levados em consideração, enquanto aplicação imparcial requer um procedimento no qual todas as características de uma situação sejam consideradas. A descrição completa de um caso concreto exige uma interpretação coerente de todas as normas válidas que são prima facie aplicáveis. Esta exigência de um sistema de normas idealmente coerente é restrita aos "paradigmas" interpretativos no caso das normas jurídicas, porque é necessário produzir julgamentos particulares sob condições limitadas de tempo escasso e conhecimento incompleto.

Palavras-chave: norma - aplicação - justificação - argumentação - imparcialidade

As considerações que seguem referem-se ao estatuto do princípio de coerência como um critério para a justificação ${ }^{1}$ de sentenças normativas. A tese é de que este critério não se refere à verdade ou correção de uma norma, mas à adequação de sua aplicação a um caso. Um primeiro

* Este texto é a tradução de uma versão inglesa abreviada que Klaus Günther apresentou para seu texto: "Ein Normativer Begriff der Kohärenz. Für eine Theorie der Juristischen Argumentation" publicado em RechtsTheorie 20, 1989. O texto inglês "A normative conception of coherence for a discursive theory of legal justification" foi publicado em Ratio Juris 2-2, 1989. Tradução de Leonel Cesarino Pessôa. 
e fraco argumento para sustentar esta tese é o de que algo semelhante a isto quiseram dizer a maioria das teorias da coerência presentes hoje na filosofia moral. De acordo com Rawls, os princípios de uma ética normativa tem que estar em equilíbrio com nossos próprios julgamentos morais. Apesar de este método estar relacionado à justificação geral de uma ética normativa e não ao problema de como podemos justificar nossos julgamentos morais particulares, suponho que esta reconstrução está baseada numa experiência de situações moralmente complexas com a qual estamos familiarizados: se e quando nossos próprios julgamentos morais num caso concreto não podem se fazer compatíveis com aqueles princípios que aceitamos como válidos. Mas estamos nesta situação apenas quando estamos aplicando normas. Só então podemos ser confrontados com resultados perturbadores de um equilíbrio reflexivo (Rawls 10, p. 38).

Explicarei minha tese da seguinte maneira. Em primeiro lugar, vou apontar porque é necessário distinguir entre a justificação e a aplicação ${ }^{2}$ de uma norma. $\mathrm{Na}$ etapa seguinte, gostaria de explicar porque o princípio da coerência é necessário para aplicação imparcial de normas. $\mathrm{Na}$ última parte, vou transpor os resultados de minha reflexão, feitos no contexto da ética do discurso, para a argumentação jurídica.

\section{O ideal de uma norma perfeita}

Uma justificação discursiva de normas válidas tem que assegurar que a observância geral de uma norma represente um interesse universal. Ela pode ser identificada por meio de uma consideração recíproca do interesse de cada um (Habermas 6, p. 75s.). Uma norma seria então justificada, se todos pudessem aceitá-la devido às razões apresentadas. Esta explicação da justificação discursiva pressupõe que algumas condições ideais de argumentação sejam preenchidas. Estas condições incluem as regras de consistência semântica necessárias para cada tipo de argumentação, regras para a organização de uma conversação e regras assegurando a participação livre e igual de todos os envolvidos (Habermas 6, p. 97s.). Somente se for observada a última regra, pode existir esperança de que um consenso sem coação e racionalmente mo- 
tivado ocorra. Satisfeita esta condição, a reciprocidade universal da validade da norma estará assegurada.

Uma outra condição ideal de justificação discursiva é a de que os participantes possam dispor de conhecimento ilimitado e tempo infinito (Günther 4, p. 45s). Se esta condição for preenchida, os participantes poderiam prever e levar em consideração todas as conseqüências e efeitos que a observância de uma regra geral pode ter para o seu interesse, em cada um dos possíveis casos de aplicação. O conhecimento não ficaria restrito a alguns tipos de situação que poderiam ser previstas contemporaneamente e usadas para ilustrar um discurso, de modo a demonstrar quais conseqüências e efeitos poderiam possivelmente ocorrer. Em vez disso, cada um dos casos possíveis de aplicação, com todas as suas características, tem que ser apresentado num discurso. Somente assim, cada um dos participantes é capaz de levar em consideração todos os efeitos da observância de uma regra geral para o seu interesse, como é exigido pelo princípio discursivo da moralidade. A quantidade de casos usados para sustentar uma norma controversa coincidiria com a quantidade de todos os casos possíveis de aplicação (Günther 4, p. 50). Uma norma de tal modo 'perfeita' poderia regular sua própria aplicação, porque cada uma das situações nas quais um interesse poderia ser violado teria sido anteriormente levada em consideração. Os participantes de um discurso estariam certos de que não haveria situação na qual a observância de uma norma violasse um interesse universal.

O conceito ${ }^{3}$ de uma norma a tal ponto 'perfeita' corresponde a nossas intuições do que significa razão prática, apesar de ele ser sob muitos aspectos problemático. Um dos problemas é a suposição irrealista de que os participantes de um discurso terão conhecimento ilimitado e tempo infinito. Contudo, esta pressuposição poderia ser aceita como sendo preenchida de maneira contrafatual. As condições de conhecimento ilimitado e tempo infinito seriam consideradas partes de outras condições pragmáticas de uma argumentação sobre a pretensão de validade de uma norma. Mas parece incerto - e aqui está outro problema conceitual - se este enlace é necessário. A tese que pretendo desenvolver é que queremos dizer coisas diferentes quando dizemos que estamos justificando uma norma imparcialmente e quando dizemos que estamos aplicando uma norma a um caso imparcialmente. Se for possível apontar que nosso entendimento pragmático da validade de uma norma não 
contém sua aplicabilidade a todos os casos, então não precisaremos mais da suposição irrealista. Uma outra conseqüência seria uma expansão do significado da razão prática: ele não contém somente a imparcialidade da justificação, mas também a imparcialidade da aplicação.

Penso que é possível mostrar que nosso uso ordinário do termo 'norma válida' está relacionado a duas questões diferentes. Estamos usando este atributo mesmo para aquelas normas que irão - como sabemos - opor-se, ao menos em alguns casos, a interesses universalizáveis. Por exemplo, todos nós sabemos (e poderíamos prever num discurso sobre validade) que a norma 'Não quebre a promessa' irá colidir com a norma 'Ajude o próximo num caso de emergência', ao menos nos casos em que podemos observar apenas um deles. Os interesses representados pela última norma são, sem dúvida, universalizáveis. Apesar disso, não admitiríamos que a norma 'Não quebre uma promessa' não é válida. Ficaríamos surpreendidos se um discurso conduzisse ao resultado oposto. Mas seria diferente se nos perguntássemos sobre a validade de uma norma como 'Sempre que você puder levar vantagem, você está autorizado a quebrar uma promessa'. Neste caso, podemos prever novamente, sem dificuldades, que a observância geral da norma violaria um interesse que é universalizável - por exemplo, o interesse daqueles que contam com uma promessa feita. Visto que as conseqüências e efeitos colaterais da observância geral da norma não são, em ambos os casos, compatíveis com um interesse universalizável, extraímos, em cada um deles, uma conclusão diferente: no primeiro caso, aceitamos a norma contestada como válida, mas não no último.

Esta diferença pode ser explicada pela teoria do discurso da seguinte maneira: A referência a uma colisão previsível de interesses desempenha um papel pragmático diferente em ambos os casos. No primeiro, ocorre uma troca de perspectivas entre os participantes do discurso por meio da consideração de todas as características do caso. Com o propósito de descobrir qual dos interesses universalizáveis poderia ser violado, os participantes referem-se à situação na qual se encontram. No outro caso, eles referem-se apenas àqueles interesses que são possivelmente violados igualmente em toda situação. Em toda situação na qual quebramos uma promessa, de acordo com a terceira norma mencionada acima (minta, se você puder levar vantagem), os interesses daquelas pessoas que contam com sua existência são violados. $O$ inte- 
resse violado pode ser identificado sem levar em consideração a situação na qual os participantes encontram-se. Eles apenas tem que se referir de maneira recíproca àqueles efeitos esperados naquelas circunstâncias que são iguais em todos os casos. Caso torne-se manifesto que, já em circunstâncias que são iguais em qualquer caso, um interesse comum será violado, a norma não pode ser aceita como válida. Neste caso, apenas um dos interesses em conflito é realmente universalizável. A troca de perspectivas entre os participantes força-os a tomar uma decisão do tipo tudo ou nada.

Se esta explicação do conceito de validade normativa é correta, então é possível aceitar tanto a obrigação de manter uma promessa como a obrigação de ajudar o próximo como normas válidas, apesar de sabermos que existem alguns casos nos quais elas irão colidir. Este aspecto

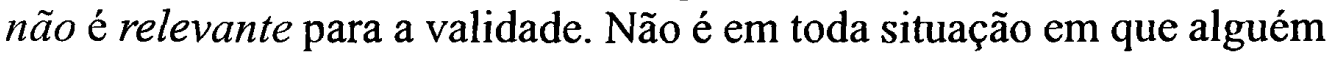
precisa de ajuda que temos simultaneamente que manter uma promessa e não é em toda situação que uma promessa deve ser mantida que temos simultaneamente um dever de ajuda. Podemos até mesmo argumentar que aqueles que precisam de ajuda querem que as promessas sejam mantidas - e vice-versa.

Mas podemos concluir que casos de colisão como estes devem ser tomados como moralmente irrelevantes? Este resultado seria contraditório com nossas intuições da razão prática. Não pode ser o resultado de um discurso sobre a validade da norma que interesses que não se refiram às circunstâncias, sendo iguais em cada caso de aplicação, possam ser violados em caso de colisão. Vamos tomar o exemplo bem conhecido de alguém chamado ' $X$ ' que prometeu a seu amigo Smith que iria a sua festa e ficou sabendo pouco tempo depois que Jones, um de seus melhores amigos, ficara doente e precisava de sua ajuda. Esta é uma situação que podemos prever num discurso sobre a validade da norma segundo a qual promessas devem ser cumpridas. Mas assim como não aceitaríamos o resultado de que a norma não é válida, por causa de uma colisão previsível, agora não estaríamos convencidos pelo argumento de que devemos abster-nos de ajudar Jones para manter a promessa. Somente se não houvesse outras circunstâncias, além daquelas levadas em consideração num discurso sobre a validade, aceitaríamos este argumento. Mas este caso nunca irá ocorrer. Por outro lado, o discurso sobre a validade não requer que levemos em consideração aque- 
las circunstâncias que são diferentes em todos os casos de aplicação. Num discurso sobre a validade, só podemos examinar aquelas características da descrição de uma situação que são iguais em todos os casos de aplicação. A validade depende somente deste exame. Mas não podemos examinar a imparcialidade da descrição com relação àqueles interesses que são representados pelas outras normas válidas. Se X agora dá como uma razão para sua falha em ajudar seu amigo a obrigação de manter a promessa, então ele terá restringido suas considerações àquelas características da situação que poderia prever no discurso sobre a validade: o fato de que fez uma promessa para Smith que agora conta com ela. $\mathrm{O}$ interesse legítimo ${ }^{4}$ de Jones somente se tornaria relevante se existisse uma obrigação ${ }^{5}$ de levar em consideração todas as caracteristicas da situação. Evidentemente a idéia da imparcialidade requer a existência desta obrigação. Contudo, não está claro ainda como justificála sem usar o ideal de uma norma perfeita.

Talvez a consideração que segue seja de grande auxílio: Se o conceito de validade está restrito à reciprocidade de interesses em circunstâncias constantes, ele não implica a aplicabilidade de uma norma, consideradas todas as coisas. Normas válidas são então aplicáveis somente prima facie se aquelas circunstâncias que elas pressupõem são válidas. Sendo as circunstâncias constantes em toda situação (com relação à norma), elas tem que ser completadas com uma 'descrição completa' da situação. Para isto, é necessário um discurso especial que eu chamo de 'discurso de aplicação'. Tão logo os participantes entrem no discurso, eles têm que abandonar a perspectiva das circunstâncias serem iguais em toda situação, pressuposta com a validade da norma. A objeção de que Jones está numa emergência, e portanto o dever de ajudar um amigo deve ser considerado, ganha agora o estatuto de um argumento. Este argumento não é dirigido contra a validade da norma em colisão, mas contra sua adequação, levadas em consideração todas as circunstâncias da situação.

Deste modo, alcançamos o ideal de uma norma perfeita por via indireta: apenas o dividimos em duas etapas distintas. Não antecipamos todas as características de cada situação a um único momento, mas em cada situação, em um determinado momento, todas suas características. Então, o problema pode ser resolvido pela aceitação de algumas normas como válidas, apesar de sabermos que elas irão colidir com outras nor- 
mas válidas em alguns casos. Se o conceito de validade é restrito àquelas circunstâncias pressupostas como constantes, agora compreendemos porque os casos interessantes de colisão não tem nada a ver com validade, mas com a adequação de uma norma que é prima facie aplicável. $\mathrm{O}$ erro que fizemos com o ideal de uma norma perfeita foi ter subsumido o conceito de adequação ao conceito de validade. Esta diferença tem um efeito colateral que pretendíamos alcançar: estamos agora prontos a dispensar as condições de conhecimento ilimitado e tempo infinito como requisitos necessários dos discursos de validade. Normalmente estamos aptos a prever, por meio de nosso conhecimento dado num limitado espaço de tempo, quais conseqüências e efeitos vão originar-se da observância geral de uma regra em circunstâncias constantes.

No fim desta seção, gostaria de discutir brevemente duas objeções que poderiam ser levantadas contra a reconstrução que propus. A primeira diz respeito à força vinculante ou 'normatividade' de normas aplicáveis apenas prima facie; a segunda diz respeito à diferença entre justificação e aplicação.

Se normas válidas são aplicáveis apenas prima facie, isto não significa que a razão prática termina com a aplicação. Lembrando o ideal de uma norma perfeita, podemos perceber o significado racional da cláusula prima facie. Os participantes de um discurso de aplicação estão obrigados a levar em consideração normas que são prima facie aplicáveis como uma razão para ou contra a justificação de um julgamento particular. A cláusula prima facie apenas significa que será insuficiente argüir que uma norma válida é aplicável a este caso. A cláusula prima facie contém um ônus recíproco de argumentação (veja-se Searle 11, p. 88 , para um argumento semelhante). Devido a este ônus de argumentação, os participantes são obrigados a dar boas razões para a modificação ou derrogação de outras normas que poderiam ser aplicadas a uma situação descrita de modo completo.

A segunda objeção diz que a diferença entre validade e adequação é supérflua, porque poderíamos aplicar um discurso de justificação a uma situação de uma maneira direta. Então todas as características que pertencem a uma descrição completa do caso também pertenceriam às circunstâncias pressupostas como constantes. Isto não é nada senão a inversão do ideal da norma perfeita. A validade de uma norma não seria subsumida na sua adequação. Em vez de uma norma que é definitiva- 
mente válida em todos os casos de aplicação, teríamos normas que são válidas em um e apenas um caso. A desvantagem desta inversão é que estamos fazendo tabula rasa moral de cada situação, porque não temos - de acordo com este modelo - normas válidas prima facie aplicáveis. A desvantagem desaparece tão logo percebemos que existem, em todas situações, diversas normas válidas aplicáveis prima facie e somente uma norma adequada.

Até este ponto, apenas estabeleci que existe uma diferença entre a justificação de uma norma válida e sua aplicação adequada. Ainda tenho que explicar o critério de adequação e os tipos de argumentos que usamos para convencer uma outra pessoa de que uma aplicação é adequada.

\section{Um outro ideal: o sistema coerente de normas válidas}

Discursos de aplicação pressupõem que as razões que usamos são normas válidas. Em vez de sua validade, os participantes discutem agora sua referência a uma situação. Somente é possível a identificação de uma norma que é adequada a uma situação se os participantes esgotaram todas as normas prima facie aplicáveis, com respeito a uma descrição completa da situação.

É supérfluo enfrentar o problema de se os participantes num discurso dispõe, de antemão, de uma descrição completa da situação e, depois, de todas as normas que são, prima facie, aplicáveis ou, ao contrário, se eles obtêm uma descrição completa somente por via indireta, a partir do conjunto de todas as referências possíveis às situações que estão incluídas numa norma e em todas as outras normas que são aplicáveis. Não existe problema com o círculo hermenêutico. A primeira questão que pode ser feita ao proponente que defende a aplicabilidade de uma norma a uma situação diz respeito à identidade de significado entre aquelas expressões incluídas na norma e aquelas incluídas na descrição do caso. Esta identidade de significado é uma condição para um tipo de justificação chamado 'justificação interna' (Wroblewski 13, p. 33) e uma condição necessária para a justificação de um julgamento particular. A fixação de um tal significado-identidade é freqüentemente chamada uma interpretação semântica ou, no âmbito da teoria do direi- 
to, "um esclarecimento dos textos de lei formalmente válidos" (Aarnio 1, p. 48). Em caso de dúvida, a interpretação semântica pode então ser justificada pela referência a precedentes, decisões judiciais ou outras fontes de direito lato sensu (Aarnio 1, p. 134; Alexy 3, p. 283). Este tipo de justificação é freqüentemente chamado 'justificação externa' (Alexy 3, p. 283).

Com este tipo de reconstrução, ainda não se esgotaram aqueles aspectos da aplicação da norma que precisam ser justificados ${ }^{6}$. Não é possível somente criticar a fixação de significado de uma norma com respeito à justificação interna e externa. Juntamente com a fixação do significado, algumas características do caso são determinadas como relevantes, enquanto outras características não são levadas em consideração. Este ato seletivo também tem que ser justificado. Um oponente poderia levantar a questão: 'Por que você refere-se somente a estas circunstâncias e não às outras?' Se tomarmos nosso exemplo novamente, Jones perguntaria a X porque ele levou em consideração somente o fato de sua promessa dada a Smith e não aquela outra característica da situação consistente no fato de que um de seus melhores amigos estava numa emergência. Um argumento que recorresse às justificações interna $\mathrm{e}$ externa não responderia a esta questão. Se $X$ argumentasse que as palavras que ele disse a Smith poderiam ser caracterizadas como uma promessa e que esta interpretação é externamente justificável ou que a norma 'Promessas devem ser mantidas' é válida, isso seria insuficiente. Estes tipos de justificações pressupõem uma descrição do caso que já foi selecionada de uma descrição completa. Não existe passagem destes tipos de justificações para aquela outra norma estabelecendo o dever de ajuda, que também é prima facie aplicável.

Se desejamos evitar este resultado, então temos que observar o princípio de que todas as características de uma situação devem ser levadas em consideração já quando nós estamos interpretando uma norma (Günther 4, p. 287; Günther 5, p. 435). A resposta à questão sobre qual das possíveis interpretações ajusta-se à descrição do caso e como ela seria justificada pode então não estar separada da consideração de outras normas que são prima facie aplicáveis. Evidentemente, não estamos fazendo isto quando usamos o argumento de que 'estas circunstâncias não são relevantes' com o propósito de responder a questão do oponente sobre porque não levamos as outras circunstâncias em con- 
sideração. Esta resposta pressupõe que já consideramos outras normas quando interpretamos a norma. Em hermenêutica isto é chamado 'précompreensão' (Vor-Verständnis) e na teoria da ciência este fenômeno é analisado como o 'contexto da descoberta'. Minha tese é de que é possível reconstruir racionalmente este aspecto no campo da aplicação de normas por meio de uma concepção de adequação.

Portanto, não é apenas a indeterminação do significado de uma expressão incluída na norma que nos dá um motivo para procurar por uma interpretação. Esta é uma razão pela qual não concordo completamente com a tese de Aarnio de que não existe diferença entre "interpretação de norma orientada pelo texto" e "interpretação de norma orientada por problema" (Aarnio 1, p. 47s). Eu acho que esta tese é incorreta se somente as justificações internas e externas são permitidas. Aarnio descreve o processo de justificação com o seguinte exemplo: "A lei Li expressa a norma: 'Se F1, então G1 deve ser'. Um jurista A deu sua opinião (ponto de vista) a respeito da lei Li na forma: no caso de $f$, tem que ser G1. Vamos chamar este ponto de vista, interpretação Il (...). Uma questão natural nesta situação é a seguinte: Por que a conseqüência G1 deve estar conectada apenas ao fato $f$ ? O jurista A deve responder que $o$ termo 'F1'no texto legal significa 'f e apenas isto'" (Aarnio 1, p. 120). Todas as justificações posteriores são do tipo externo, isto é, elas dizem respeito apenas à validade desta interpretação. Mas a questão do oponente ainda não foi respondida completamente. 'No caso de $f$ poderiam existir - mesmo num caso hipotético como este - algumas outras normas como Lk, Lm etc., aplicáveis prima facie. Então, poderia acontecer que também G2, G3 etc. devessem ser aplicadas neste caso. Mas não podemos considerar estas normas sem imaginar a totalidade de suas características 'no caso de $f$ '. Então, temos que mostrar que Il é a interpretação adequada 'no caso de $f$ '. Mas qual o critério desta adequação?

Vamos resumir nosso exemplo. O julgamento singular

\section{(N1) $\mathrm{X}$ deve ajudar seu amigo Jones}

poderia ser justificado de diversos modos. Mas existe apenas uma justificação adequada. É possível justificar o julgamento particular por meio de uma referência à norma 
(NI) No caso de emergência, você deve ajudar seu amigo

Não existe dúvida sobre a identidade de significado entre o predicado incluído na norma e a descrição do caso. A interpretação possível que não menciono aqui poderia também ser justificada externamente. A justificação do julgamento particular está baseada numa norma válida que é aceita universalmente. Mas para descobrir se o julgamento singular está baseado numa aplicação adequada da norma, a justificação tem que ser mais complexa. Assim como uma norma válida NI é apenas prima facie aplicável - e o oponente poderia perguntar porque o proponente não observou a outra norma que também poderia ser aplicada:

(NII) Promessas devem ser mantidas

Porque a cláusula prima facie está nos obrigando a levar todas as características da situação em consideração, temos agora que incluir esta norma em nosso discurso - porque ela é uma norma válida que seria violada, se observássemos a outra norma (NI). O proponente que defende a adequação de (NI) tem agora que assumir o ônus da argumentação. Ele não pode considerar (NII) como inválida. Então, somente pode apontar para o âmbito e para o grau em que as normas em conflito são compatíveis neste caso. Neste nível, inicia-se uma interpretação coerente de todas as normas aplicáveis à situação, descrita de modo completo. Temos que esgotar o conteúdo proposicional das normas. Para este propósito, precisamos de outro material normativo como princípios ou explicações, com a característica de um princípio. Por exemplo, o proponente poderia argumentar que a instituição da promessa não tem o propósito de parar uma ação salva-vidas. Por meio desta interpretação, podemos determinar o grau e o âmbito da restrição de uma norma válida num determinado caso ou, se for possível, podemos usar uma regra de prioridade como a que nós ainda esperamos todo o tempo:

(NIII) Você deve quebrar uma promessa desprezível para ajudar seu amigo que está numa emergência 
No mundo simples de nosso exemplo, esta norma é o resultado de uma interpretação coerente de todas aquelas normas que podem ser aplicadas prima facie a uma descrição completa do caso. É a norma adequada e, de acordo com critérios interno e externo, uma das diversas possíveis justificações corretas do julgamento singular: (N1) Você deve ajudar seu amigo Jones.

Agora é evidente que uma justificação satisfatória do julgamento singular (NI) não se refere somente à norma (NI), apesar de uma justificação interna e externa serem possíveis. Este tipo de justificação (R1) é menos complexo que uma aplicação adequada (R2), que leva em consideração a norma prima facie aplicável (NII). (R2) está baseado numa descrição do caso que é mais complexa - e no mundo simples do nosso exemplo, mesmo completa - de modo que a justificação inclui uma outra norma aplicável prima facie e o interesse universalizável correspondente. Apenas devido à obrigação de aplicar normas válidas de uma maneira coerente a situações descritas completamente, pode ser assegurado que normas válidas não sejam restringidas ou postas de lado sem qualquer razão.

Depois deste esquema bastante breve de um processo para a aplicação adequada de normas válidas, deixe-me retornar à diferença entre aplicação e justificação. Deste modo, alcançamos um processo discursivo que leva em consideração aquelas normas conflitantes, irrelevantes para a validade do dever de manter uma promessa. Se tivéssemos interpretado esta norma coerentemente, numa situação descrita de maneira completa, poderíamos agora dizer também que a obrigação de manter uma promessa nunca quis dizer nada diferente de admitir a prioridade da obrigação de ajudar um amigo. Desta maneira, teríamos alcançado o ideal de uma norma perfeita reconstrutivamente: Os conceitos de validade e adequação significariam o mesmo se e somente se pudéssemos justificar antecipadamente as conseqüências da observância geral da norma para cada um dos possíveis casos de aplicação. Deste modo, teríamos que aplicar uma norma válida como se tivéssemos previsto esta situação num discurso sob as condições de conhecimento ilimitado e tempo infinito. Então, esta norma válida seria também a única adequada. Mas, por outro lado, não podemos verificar esta pretensão por meio de um discurso sobre a validade, porque somente podemos considerar as circunstâncias que são iguais em toda situação. A verificação desta 
pretensão seria deslocada no tempo para os discursos de aplicação. Se estamos agora aceitando a norma NI como válida, apesar de saber que ela poderia colidir como uma norma como NII, pressupomos que todas as normas válidas constituem, em última análise, um sistema ideal coerente que dá a cada caso exatamente uma resposta correta (isto é, adequada) - em outros termos: a razão prática não se contradiz ela mesma. Discursos de aplicação representam o processo por meio do qual verificamos esta pretensão em relação a cada uma das normas válidas.

É claro que nunca alcançaremos este ideal de um sistema coerente de todas as normas válidas. Estamos trabalhando na sua realização aproximada em toda situação na qual a descrição completa altera a matriz das normas conflitantes. Se toda norma válida requer um complemento coerente com todas as outras normas que podem ser aplicadas prima facie à situação, então o significado da norma está se alterando em cada uma das situações. Desta maneira, dependemos da história, cada momento que encaramos uma situação que não poderíamos prever e que nos força a alterar nossa interpretação de todas as normas que aceitamos como válidas. Por outro lado, estamos antecipando o fim da história com o ideal de um sistema coerente de todas as normas válidas que permitem uma única resposta correta a cada situação. Mas, na realidade, temos somente 'paradigmas' que consistem em normas válidas e transitivamente ordenadas.

Normalmente, nos referimos a uma destas ordens transitivas, quando nos ocupamos com um caso típico de colisão. Estes paradigmas são determinados por uma forma de vida comum, que é partilhada. Então, por exemplo, toda forma de vida tem sua própria regra de prioridade a respeito da relação entre liberdade e igualdade. Apesar disso, dois aspectos destes paradigmas podem ser criticados por meio do discurso, independentemente de qual seja a forma de vida: a validade das normas singulares, se os interesses estão se alterando e a relação de coerência entre as normas válidas, se as descrições das situações estão se alterando. 


\section{Uma sugestão sobre como interpretar o conceito de coerên- cia na teoria jurídica}

Na última seção pretendo defender a tese de que o sistema legal de uma sociedade tem que ser interpretado como um paradigma de um sistema de normas válidas, em última análise, coerente. De acordo com esta sugestão, um sistema jurídico pode ser criticado pelos mesmos dois tipos de motivos, como no caso das normas morais: as normas jurídicas tem que ser válidas no sentido de uma teoria do discurso e o sistema coerente de normas jurídicas pretende dar uma resposta adequada a todos os casos. Além disso, um sistema jurídico é caracterizado por um outro traço, que estabelece uma distinção com relação a um sistema coerente de normas morais e explica porque um sistema jurídico não é um sistema ideal e coerente de todas as normas válidas. Nem um discurso de justificação nem um discurso de aplicação asseguram que as normas válidas sejam realmente observadas por todos. Uma expectativa correspondente somente pode ser estabilizada, se existir segurança jurídica numa sociedade e as decisões jurídicas puderem ser previstas por todos. Agora, o problema acima mencionado, de que não temos condições de argumentar em condições de conhecimento ilimitado e tempo infinito, torna-se um problema funcional para a estabilização de expectativas. Este fenômeno chamado de 'dupla contingência' (Parsons 9 , p. 15) diminuiria, se dispuséssemos apenas de normas perfeitas.

Um dos modos por meio dos quais uma sociedade lida com estas exigências funcionais é colocar normas válidas numa ordem transitiva, na qual os casos típicos de colisão sejam antecipadamente interpretados. Esta é a razão pela qual não existe 'doutrina' em ética. Uma norma jurídica é aplicada de uma maneira adequada, se ela coincide com todo material jurídico (isto é, lei ou direito consuetudinário, objetivos legislativos, precedentes, doutrina jurídica etc.). De acordo com minha sugestão, podemos agora dizer que a coerência da interpretação de uma norma está somente representado o ideal de um sistema, em última análise, coerente. Sempre que usarmos as regras e formas de justificação externa, estamos nos referindo a este ideal ao menos implicitamente. Isto torna-se aparente quando o apoio de uma justificação pelos meios de uma justificação externa conduz a um resultado inadequado. Visto que não conseguimos prever cada caso de colisão, mesmo dentro de um 
sistema jurídico, temos que encarar aquelas situações nas quais uma interpretação coerente de todas as normas prima facie aplicáveis somente é possível por referência a princípios morais.

Uma outra conseqüência de minha sugestão é uma resposta diferente à questão de como interpretar o estatuto de validade de uma interpretação da norma. Este problema nasce se os atos de fala regulativos (normas) são interpretados de maneira unilateral como prescrições. De acordo com esta explicação, que foi proposta por von Wright 12, Aarnio 1 e MacCormick 7 (mutatis mutandis), somente dois tipos de proposição sobre uma norma podem ser racionalmente criticados: "Proposições normativas", como sentenças sobre a existência de uma norma ou seu conteúdo proposicional, são descritivas e passíveis de serem verdadeiras ou falsas. 'Controvérsias normativas' ou 'pontos-de-vista normativos', como interpretações do texto do direito, podem ser verdadeiras ou falsas somente num sentido limitado. Suas verdades são relativas ao grupo de proposições que obtemos do material jurídico. Qual das interpretações possíveis será, em última análise, aceita depende da avaliação partilhada pelos membros de uma forma de vida. Neste nível, a razão prática tem que parar (MacCormick 8) ou ceder espaço para 'aceitabilidade racional' fundada em valores partilhados (Aarnio \& Alexy $\&$ Peczenik 2). De acordo com minha sugestão, não estamos preocupados com a questão da verdade, mas com uma aplicação adequada de normas válidas. Se um conflito entre interpretações concorrentes não é solúvel por meio de um discurso de aplicação, então poderia ser o caso de uma das normas não ser universalizável em circunstâncias consideradas constantes. Então temos que considerar um discurso sobre a justificação de sua validade. 


\begin{abstract}
The author introduces a normative conception of coherence, derived from a pragmatic interpretation of the application of norms to concrete cases. A distinction is made between the justification of a norm and its application. In the case of moral norms, justification and application can be analysed as two different discursive procedures which give rise to different aspects of the principle of impartiality. Impartial justification requires a procedure by which all interests concerned are taken into account whereas impartial application requires a procedure where all features of a situation are considered. The complete description of a concrete case makes necessary a coherent interpretation of all valid norms which are prima facie applicable. This requirement of na ideal coherent system of norms is restricted to interpretative "paradigms" in the case of legal norms, because it is necessary to produce singular judgments under the restrictive conditions of scarce time and incomplete knowledge.
\end{abstract} Key-words: norm - application - justification - argumentation - impartiality

\title{
Notas
}

1. Neste trecho, o termo justificação não está sendo usado, como será mais à frente, tendo em vista a distinção que o autor estabeleceu entre aplicação e justificação de uma norma.

2. Na versão alemã, Begründung und Anwendung.

3. $\mathrm{Na}$ versão inglesa a palavra usada é 'concept', enquanto na versão alemã o termo usado é 'Ideal'.

4. Na versão alemã, universalizável.

5. Na versão alemã, um dever moral.

6. O termo justificação neste caso está sendo usado em sentido amplo, sem referência à dicotomia justificação/aplicação. 


\section{Referências Bibliográficas}

1. AARNIO, A. The rational as reasonable. A treatise on legal justification. Dordrecht, Reidel, 1987.

2. AARNIO, A. \& ALEXY, R. \& PECZENIK, A. "The foundation of leal reasoning". Rechtstheorie, 12, p. 133-58, 257-79, 423-48, 1981.

3. ALEXY, R. Theorie der juristischen Argumentation. Frankfurt a.M., Suhrkamp, 1983.

4. GÜNTHER, K. Der Sinn für Angemessenheit. Anwendungsdiskurse in Moral und Recht. Frankfurt a.M., Suhrkamp, 1988.

5.

"Pragmatic and functional indeterminacy of law". In: Ch. JOERGES \& TRUBEK, D. (eds.). Critical legal thought: an american-german debate. Baden-Baden, Nomos, 1989.

6. HABERMAS, J. "Diskursethik. Notizien zu einem Begründungsprogramm". In: . Moralbewusstein und kommunicatives Handeln. Frankfurt a.M., Suhrkamp, 1983.

7. MACCORMICK, N. Legal reasoning and legal theory. Oxford, Clarendon, 1978.

8. "Coherence in legal justification". In: KRAWIETz, W. et alli (ed.). Theorie der Normen. Festgabe für Ota Weinberger zum 65 Geburtstag. Berlim, Duncker \& Humblot, 1984.

9. PARSONS, T. et alli. Toward a general theory of action. Cambridge Mass., Harvard University, 1954.

10. RAWLS, J. Eine Theorie der Geschichtgkeit. VETTER, H. (trad.). Frankfurt A.M., Suhrkamp, 1979.

11. SEARLE, J. "Prima Facie Obligations". In: Pratical reasoning. RAZ J. (ed). Oxford University, 1978. 
12. VON WRIGHT, G. H. "Is and Ought". In: Man, law and modern forms of life. BULYGIN et alli (eds.). Dordrecht, Reidel, 1985.

13. WRÓBLEWSKI, J. "Legal syllogism and rationality of judicial decision”. Rechtstheorie, 5, p. 33-46, 1974. 